\title{
Inflammatory patterns of antrochoanal polyps in the pediatric age group
}

Huiwen Zheng ${ }^{1 \dagger}$, Lixing Tang ${ }^{2 \dagger}$, Beibei Song ${ }^{2}$, Xiaojian Yang ${ }^{2}$, Ping Chu' , Shujing Han ${ }^{1}$, Pengpeng Wang ${ }^{2}$, Jie Lu ${ }^{1 *}$, Wentong $\mathrm{Ge}^{1,2^{*}}$ and Xin $\mathrm{Ni}^{1,2^{*}}$

\begin{abstract}
Background: The pathogenesis and etiology of antrochoanal polyps (ACPs) remains obscure. This study aimed to characterize the inflammatory profiles and investigate the effect of atopy on the pathogenesis of pediatric ACPs.

Methods: Thirty-three ACP patients and ten control subjects were enrolled from January to December 2017. The severity of individual nasal symptoms was scored on a visual analogue scale (VAS). The serum total immunoglobulin $E$ (IgE) and cytokines level was measured by multiplexed luminex assay.

Results: There was no significant difference in VAS scores and counts of inflammatory cells between atopic and nonatopic ACP. No difference in IFNY, IL-4, IL-5, IL-13, IL-17A and IL-25 was found between control and whole ACP, nonatopic and atopic ACP. Significantly increased levels of IL- 6 and IL-10 were found in ACP compared with control. For neutrophil chemotactic factor, significant increases of IL-8 and GRO were observed in ACP, but for eosinophil chemotactic factor, no difference was found in RANTES and GM-CSF. IL-6 level was positively correlated with IL-8, MCP1, and GRO level, and IL-10 level was positively correlated with IL-4 and IL-13 in ACP subjects.

Conclusion: Nasal obstruction was the most common symptom in ACPs in children. Allergic condition may have a poor role in the pathogenesis of ACPs. IL-6 plays a crucial role in the pathogenesis of neutrophilic inflammation in patients with ACPs and may provide a new treatment strategy for ACPs in children. Treg cell associated cytokine IL-10 was involved in the inflammatory pathophysiological process of ACPs and played a certain regulatory role.
\end{abstract}

Keywords: Antrochoanal polyps, Atopy, Cytokine

\section{Background}

Antrochoanal polyps (ACPs) are benign polypoid lesions originating from the mucosa of the maxillary sinus, passing through the maxillary sinus ostium, and extending into the choana [1-3]. Although there are a few cases of bilateral ACPs demonstrated in literature, ACPs are invariably unilateral, and occur more commonly in children than in adults, with approximately $4-6 \%$ of all

\footnotetext{
*Correspondence: lujiebch@163.com; gwt@bch.com.cn; nixin@bch.com. $\mathrm{cn}$

${ }^{\dagger}$ Huiwen Zheng and Lixing Tang contributed equally

1 Beijing Key Laboratory for Pediatric Diseases of Otolaryngology, Head and Neck Surgery, MOE Key Laboratory of Major Diseases in Children, Beijing Pediatric Research Institute, Beijing Children's Hospital, Capital Medical University, National Center for Children's Health, Beijing, China Full list of author information is available at the end of the article
}

nasal polyps in general population and about $35 \%$ of all pediatric cases of nasal polyps $[4,5]$.

The pathogenesis and etiology of ACPs remains obscure, and cystic fibrosis and chronic sinusitis implicated [6]. Although some have proposed ACPs as a complication of chronic inflammatory antral disease, allergic polyps (abundant eosinophils) were found to be more common than inflammatory polyps (abundant neutrophils) among children by histopathology, and Chen and his colleagues reported that $50 \%$ of the patient had allergic diatheses in their review of ACPs in the pediatric population $[7,8]$.

Studies of comprehensive atopic response and inflammatory pattern have been conducted to understand the pathogenesis of nasal polyps and guide clinical therapies $[9,10]$, but such studies in ACPs are lacking. In this study, we attempted to investigate the effect of 
atopy on the pathogenesis of ACPs and characterize the inflammatory profiles in the pediatric population.

\section{Patients and methods Study population}

This study was approved by the Ethics Committee of Beijing Children's Hospital, Capital Medical University and written informed consent was obtained from all participants. This study was performed in thirty-three ACP patients who underwent endoscopic surgery from January to December 2017. The serum total immunoglobulin E (IgE) level was measured to evaluate the atopic status of the patients, and $>333 \mathrm{IU} / \mathrm{ml}$ (800 ng/ $\mathrm{ml}$ ) was considered as atopic ACP. Subjects who had immunodeficiencies, bronchiectasis, diabetes mellitus, cystic fibrosis, asthma or upper airway infections were excluded from the study. Control subjects were inferior turbinate mucosa from those underwent posterior nostril closure with no history of inflammatory nasal complaints. The severity of individual nasal symptoms was scored on a visual analogue scale (VAS) of 0 to 10 .

\section{Immunological measurement}

Fresh obtained tissue samples were frozen in liquid nitrogen and stored at $-80{ }^{\circ} \mathrm{C}$. As reported [11], $0.1 \mathrm{~g}$ of each frozen tissue was added to $1 \mathrm{ml}$ of $0.9 \%$ $\mathrm{NaCl}$ solution, followed by homogenized on ice and centrifuged at $3000 \mathrm{rpm}$ for $10 \mathrm{~min}$ at $4{ }^{\circ} \mathrm{C}$, and the supernatants were collected and stored at $-80{ }^{\circ} \mathrm{C}$ for further cytokines analysis. All samples were analyzed for interleukin (IL)-17A, Interferon (IFN) $\gamma$, growth related oncogene (GRO), IL-8, IL-13, macrophage inflammatory protein (MIP)-1 $\alpha$, granulocyte-macrophage colonystimulating factor (GM-CSF), monocyte chemotactic protein-1 (MCP-1), regulated on activation, normal $\mathrm{T}$ cell expressed and secreted (RANTES) and tumor necrosis factor (TNF) $\alpha$ using human cytokine/chemokine panel I, IL-25, IL-1 $\beta$, IL-5, IL-6, IL-10, IL-4, IL-21 and IL-33 using human Th17 panel (MILLIPLEX MAP KIT).

\section{Statistics}

All statistical analyses were performed using the SPSS version 16.0 software. Data was expressed as box-andwhisker plots and median interquartile range (IQR). The Kruskal-Wallis $\mathrm{H}$ test was used to assess the significance of intergroup variability using paired comparisons, and the Mann Whitney U 2-tailed test was used to assess significance for between-group comparisons. The Spearman test was used to determine correlations. $P$ values of less than 0.05 were considered statistically significant.

\section{Results}

\section{Clinical data}

In total, 43 subjects were enrolled in this study, including 33 ACP patients, and 10 control subjects. The clinical data was summarized in Table 1 . Both atopic and nonatopic ACP patients had higher VAS scores of nasal discharge and overall burden compared with those in control. Nevertheless, no significant difference was observed in VAS scores of three other individual major

Table 1 Patients' clinical data

\begin{tabular}{|c|c|c|c|c|c|c|c|c|}
\hline & \multicolumn{4}{|l|}{ Number } & \multicolumn{4}{|l|}{$P$ value } \\
\hline & $\begin{array}{l}\text { Control } \\
(n=10)\end{array}$ & $\mathrm{ACP}(n=33)$ & $N-A C P(n=23)$ & $A-A C P(n=10)$ & Control vs ACP & $\begin{array}{l}\text { Control vs } \\
\mathrm{N}-\mathrm{ACP}\end{array}$ & $\begin{array}{l}\text { Control vs } \\
\text { A-ACP }\end{array}$ & N-ACP vs A-ACP \\
\hline Gender, male, n (\%) & $7(70)$ & $24(72.7)$ & $16(69.6)$ & $6(60)$ & - & - & - & - \\
\hline Age (years) & $9(7,10)$ & $9(8,11)$ & $9(7,11)$ & $9(9,11)$ & 0.283 & 0.920 & 0.333 & 0.239 \\
\hline Serum lgE & - & $\begin{array}{l}558.75(333.50 \\
899.75)\end{array}$ & $\begin{array}{c}368(311.88 \\
623.63)\end{array}$ & $\begin{array}{c}1059(902.88 \\
1726.38)\end{array}$ & - & - & - & - \\
\hline \multicolumn{9}{|l|}{ VAS score } \\
\hline Sneeze & $0(0,0.5)$ & $0(0,1)$ & $0(0,1)$ & $0(0,1.25)$ & 0.577 & 0.672 & 0.480 & 0.596 \\
\hline Nasal discharge & $1(0,1)$ & $2(0,2)$ & $2(0.25,2.75)$ & $2(1.75,3)$ & 0.002 & 0.003 & 0.002 & 0.148 \\
\hline Nasal obstruction & $2(0.25,2.75)$ & $2(2,2)$ & $2(2,2)$ & $2(1.75,2.25)$ & 0.262 & 0.423 & 0.306 & 0.628 \\
\hline Nasal itch & $2(2,2)$ & $0(0,1)$ & $0(0,1)$ & $0(0,0.5)$ & 0.312 & 0.136 & 0.769 & 0.573 \\
\hline Overall burden & $2(2,3)$ & $4(3,5)$ & $4(3,5)$ & $5(3,7)$ & $<0.001$ & $<0.001$ & 0.020 & 0.401 \\
\hline \multicolumn{9}{|c|}{ Counts of inflammatory cells in peripheral blood } \\
\hline Neutrophile $\left(1 \times 10^{9} / \mathrm{L}\right)$ & $4.12(3.18,4.85)$ & $3.61(2.88,5.53)$ & $3.37(2.73,4.08)$ & $5.65(3.27,6.34)$ & 0.878 & 0.358 & 0.153 & 0.056 \\
\hline Lymphocyte $\left(1 \times 10^{9} / L\right)$ & $3.16(2.24,4.27)$ & $2.47(2.02,2.97)$ & $2.56(2.10,3.18)$ & $2.09(1.99,2.91)$ & 0.140 & 0.214 & 0.082 & 0.254 \\
\hline Monocyte $\left(1 \times 10^{9} / \mathrm{L}\right)$ & $0.39(0.25,0.46)$ & $0.36(0.28,0.43)$ & $0.33(0.28,0.42)$ & $0.36(0.28,0.53)$ & 0.887 & 0.562 & 0.818 & 0.584 \\
\hline Eosinophil $\left(1 \times 10^{9} / \mathrm{L}\right)$ & $0.14(0.07,0.24)$ & $0.10(0.06,0.16)$ & $0.10(0.08,0.16)$ & $0.10(0.03,0.21)$ & 0.354 & 0.448 & 0.759 & 0.719 \\
\hline
\end{tabular}


symptoms and in inflammatory cells between atopic and nonatopic ACP.

\section{Type 1, 2, and 17 cytokine levels in ACP}

When compared all ACP and atopic ACP to control group, all had higher TNFa levels (control vs all ACP vs atopic ACP: 6.93 [5.23, 11.53] vs 11.01 [9.34, $15.61]$ vs $11.01[8.71,14.65])(P=0.024$, and $P=0.036$, respectively), but no difference was discovered between nonatopic ACP (11.73 [9.41, 20.07]) and control (Fig. 1). Besides, no significant difference in $\mathrm{T}_{\mathrm{H}} 1$ associated cytokine IFN $\gamma$ was found among different study groups (control vs all ACP vs nonatopic ACP vs atopic ACP: $13.83[8.62,24.80]$ vs $20.18[15.43,30.16]$ vs 20.46 [16.09, $26.87]$ vs $19.72[11.09,56.82])$.

No difference in the levels of $\mathrm{T}_{\mathrm{H}} 2$ related cytokines (IL-4, IL-5, and IL-13) was revealed among different study groups (control vs all ACP vs nonatopic ACP vs atopic ACP: $0.10[0.04,0.29]$ vs $0.06[0.04,0.09]$ vs 0.07 $[0.05,0.09]$ vs $0.06[0.03,0.19]$ for IL-4; $3.05[1.90,6.58]$ vs $4.14[3.17,5.84]$ vs $4.03[3.36,5.71]$ vs $5.58[2.95,9.23]$ for IL-5; 11.18 [6.22, 14.20] vs 12.52 [8.51, 15.96] vs 12.79 $[9.58,15.43]$ vs $14.05[8.20,18.21]$ for IL-13).

For $\mathrm{T}_{\mathrm{H}} 17$ cytokines (IL-17A and IL-25), no significant difference was observed between control and whole ACP, nonatopic and atopic ACP (control vs all ACP vs nonatopic ACP vs atopic ACP: 8.37 [5.17, 14.92] vs 8.32 $[5.76,9.64]$ vs $8.45[5.99,9.68]$ vs $6.23[4.03,19.43]$ for IL- $17 \mathrm{~A}, 0.00[0.00,0.05]$ vs $0.00[0.00,0.00]$ vs $0.00[0.00$, $0.00]$ vs $0.00[0.00,0.00]$ for IL-25).

\section{IL-6 and IL-10 expression in ACP}

Significantly increased levels of IL-6, a proinflammatory cytokine, were found in whole ACP (218.44 [48.01,
717.18]), atopic (103.89 [68.88, 294.51]) and nonatopic ACP (273.84 [33.14, 2728.11]) compared with those in control $(17.31[11.69,28.63])(P=0.004, P=0.027$, and $P=0.011$, respectively), and between atopic and nonatopic ACP $(P=0.021)$ (Fig. 2$)$.

Likewise, IL-10 (Fig. 3), a Treg related cytokine, was increased in whole ACP $(3.20[2.35,3.90])$ compared to controls $(1.87[1.49,3.16])(P=0.047)$, but no significant difference was found in control compared with those in atopic $(3.58[2.35,4.10])$ and nonatopic ACP (3.24 [2.63, $3.67])$.

\section{Chemokine expression in ACP}

IL-8, an important chemokine for neutrophils, was increased in whole ACP $(971.93$ [498.15, 2070.40]), atopic (844.10 [431.77, 1732.75]) and nonatopic ACP (1085.71 $[478.35,2706.34])$ than that in control (69.82 [45.46, 205.68]) $(P<0.001, P=0.010$, and $P=0.007$, respectively) (Fig. 4). Similar to IL-8, another neutrophil chemotactic factor GRO was observed significant increase in whole ACP (2724.81 [1511.21, 4980.43]), atopic (1965.91 [1333.36, 3218.19]) and nonatopic ACP (2754.90 $[1106.60,5525.88])$ than that in control (968.74 [274.43, 1304.88] $)(P<0.001, P=0.022$, and $P<0.001$, respectively $)$ (Fig. 4).

MCP-1, which can attract different inflammatory cells, a statistically significant increase was found in whole ACP (1558.61 [939.01, 3147.30]) and nonatopic ACP (1796.90 [1103.00, 3919.84]) compared to control (392.34 $[285.09,1064.47])$, whereas levels in atopic ACP did not differ from control group (Fig. 4).

No differences in RANTES and GM-CSF, chemoattractant for eosinophils, were found among different study groups (control vs all ACP vs nonatopic

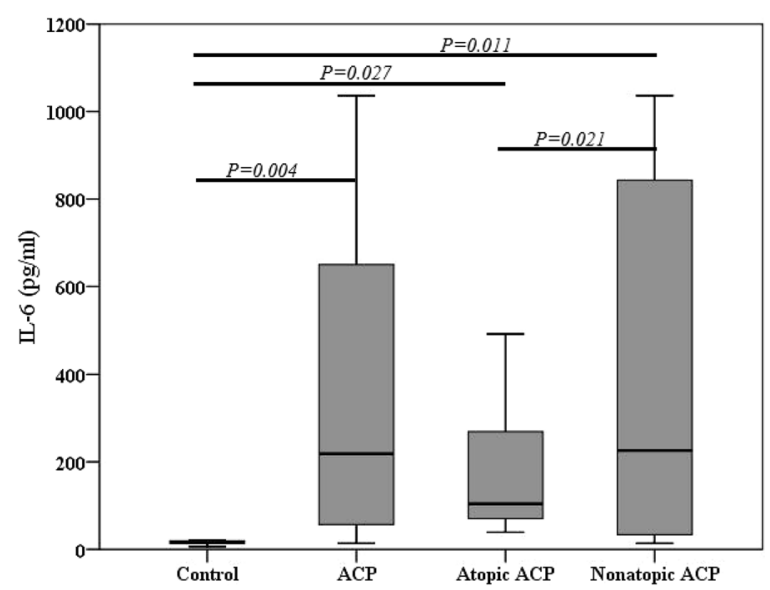

Fig. 2 Levels of IL-6 in different groups. ACP antrochoanal polyp, IL-6 interleukin-6

Fig. 1 Levels of TNF-ain different groups. ACP antrochoanal polyp, TNF-a tumor necrosis factor-a 


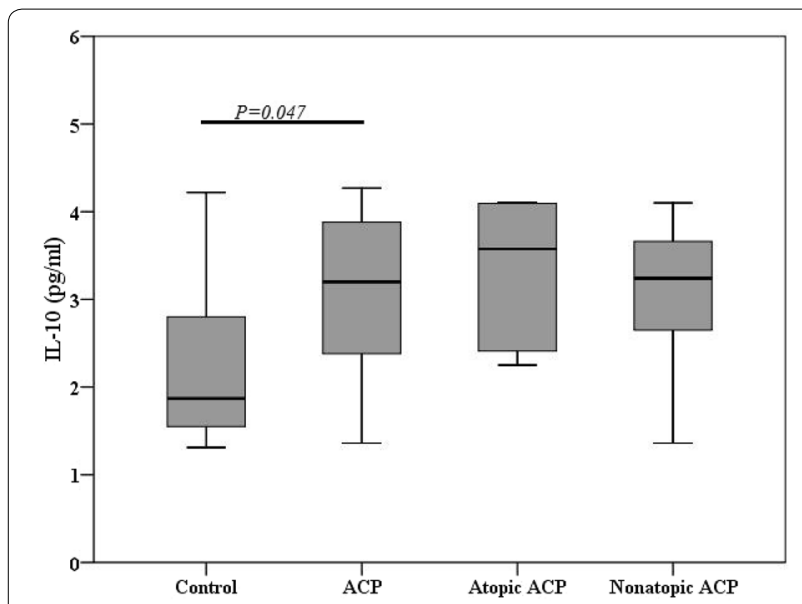

Fig. 3 Levels of IL-10 in different groups. ACP Antrochoanal polyp, IL-10 interleukin-10
ACP vs atopic ACP: 3222.17 [1695.07, 6901.23] vs 3508.25 [1831.22, 6191.21] vs 3598.19 [2091.21, 5236.95] vs 2801.46 [1781.28, 8529.95] for RANTES; 4.15 [2.80, $8.59]$ vs $4.64[3.82,6.26]$ vs $4.45[3.84,5.91]$ vs 5.98 [3.53, 10.00] for GM-CSF).

MIP-1 $\alpha$ ascribed to attract granulocytes was not differently expressed among different study groups (control vs all ACP vs nonatopic ACP vs atopic ACP: $16.84[11.09,46.06]$ vs $17.87[14.63,35.31]$ vs 18.03 $[14.72,33.77]$ vs $18.69[14.70,36.03])$.

\section{The correlation between IL-6, IL-10 expression} and inflammatory marker level

IL-6 level was positively correlated with IL-8 level $\left(r^{2}=0.6228, \quad P<0.0001\right), \quad$ IL-1 $\beta \quad$ level $\quad\left(r^{2}=0.1433\right.$, $P=0.0298)$, MCP1 level $\left(r^{2}=0.3355, P=0.0004\right)$, and GRO level $\left(r^{2}=0.1295, P=0.0397\right)$ in ACP subjects (Fig. 5). IL-10 level was positively correlated with IL-4
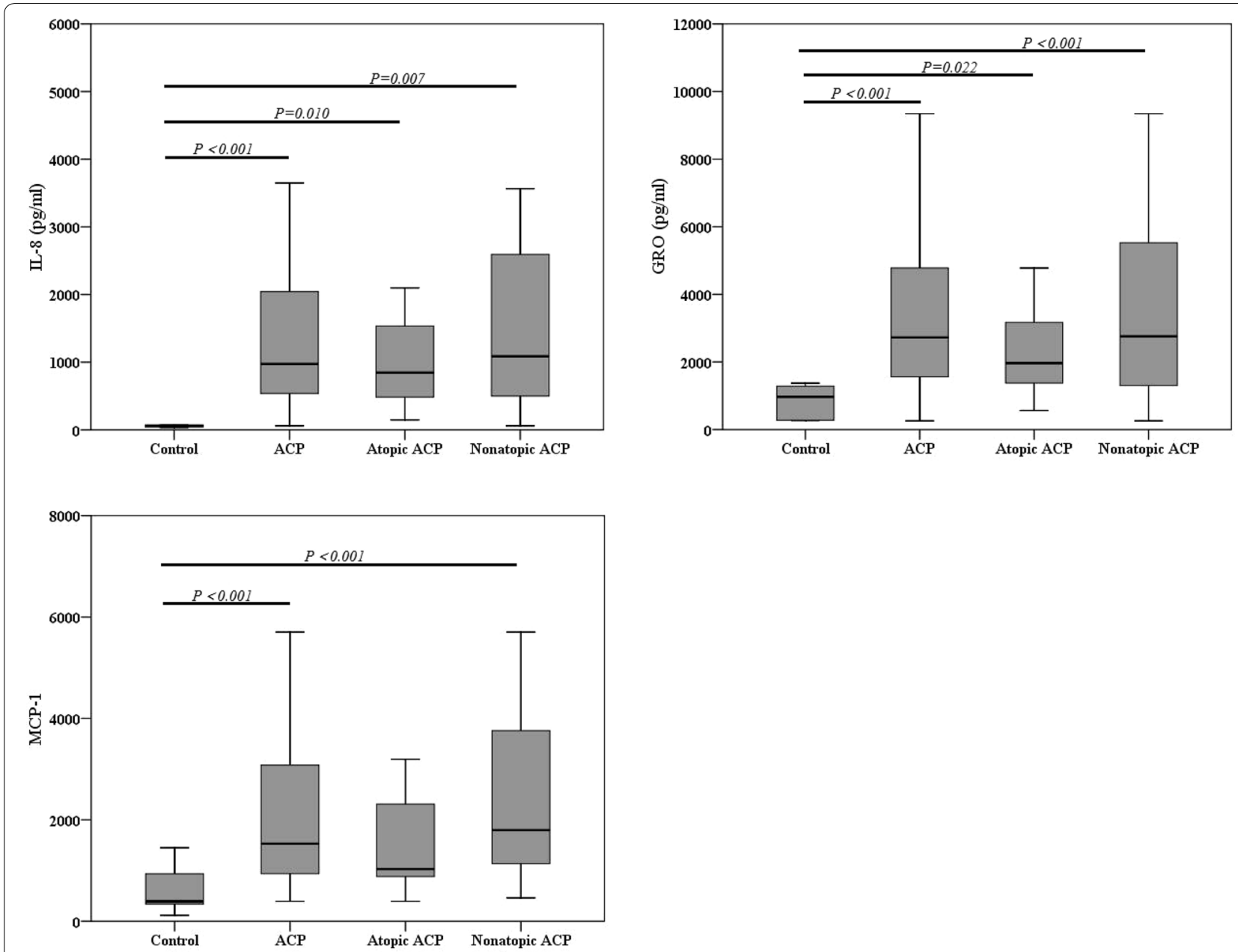

Fig. 4 Levels of IL-8, GRO, and MCP-1 in different groups. ACP antrochoanal polyp, IL-8 interleukin-8, GRO growth related oncogene, MCP-1 monocyte chemotactic protein-1 

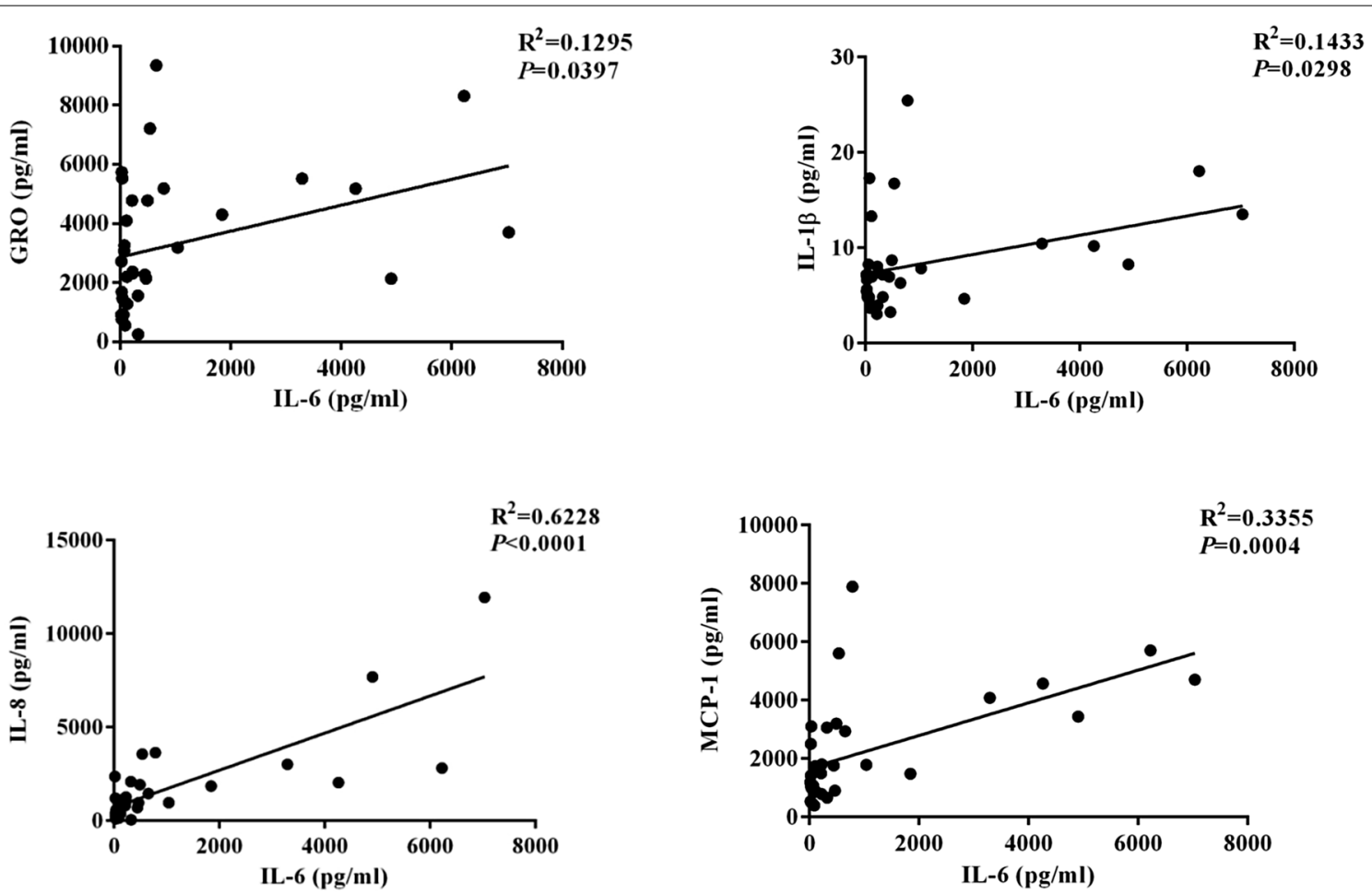

Fig. 5 Correlation between IL-6 expression and GRO, IL-1 $\beta$, IL-8, and MCP-1 level in antrochoanal polyps. IL-6 interleukin-6, GRO growth related oncogene, IL-1 $\beta$ interleukin- $\beta, I L-8$ interleukin-8, MCP-1 monocyte chemotactic protein-1

level $\left(r^{2}=0.2797, P=0.0016\right)$, IL-13 level $\left(r^{2}=0.3094\right.$, $P=0.0008)$ in ACP subjects (Fig. 6).

\section{Discussion}

ACPs in children are uncommon but occur at a higher rate than that in the adult population. Several previous studies showed that males were more common in ACPs [12-14], and our data confirmed this characteristic. Clinically, ACPs usually present with nasal obstruction and drainage, but the symptoms of dyspnea, epistaxis, dysphagia and postnasal drip were observed in severe cases [15]. In this study, the symptoms of ACPs were similar to those of many paranasal sinus diseases, including sneezing, rhinorrhea, itching, and nasal obstruction the most common symptom.

Allergic background of ACP patients was reported in some cases, which were significantly more common than inflammatory polyps among children on histopathology [8]. Previous studies have demonstrated that compared to nonatopic CRS, higher sneezing scores and reduced
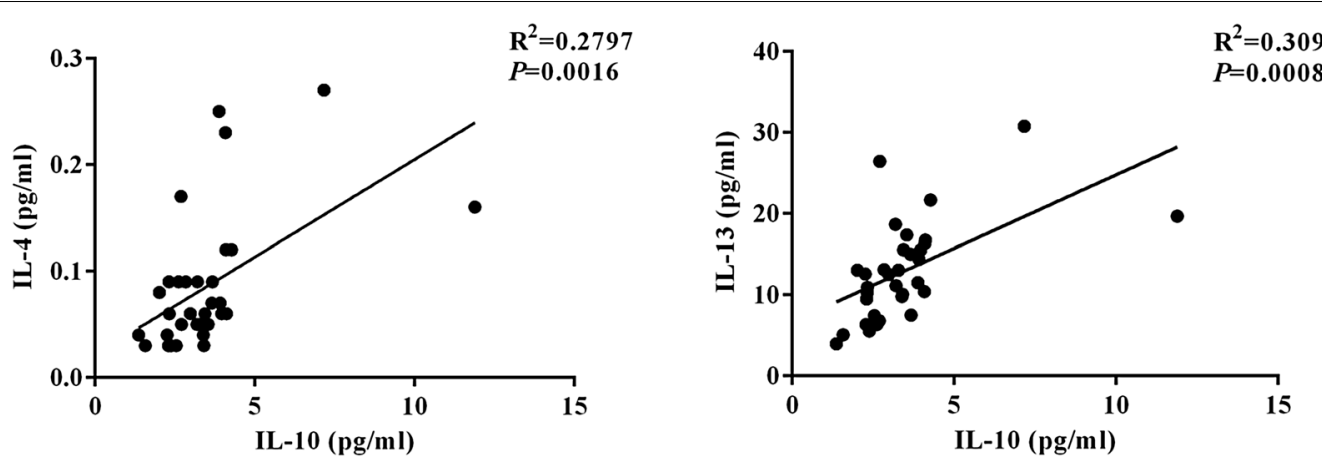

Fig. 6 Correlation between IL-10 expression and IL-4 and IL-13 level in antrochoanal polyps. IL-10 interleukin-10, IL-4 interleukin-4, IL-13 interleukin-13 
productivity and concentration was observed in atopic CRS patients [16]. But no studies focused on atopic and nonatopic ACPs patients, in the present study, we have identified $10(30.3 \%, 10 / 33)$ allergic ACP cases, but failed to find a significant effect of atopy on symptomatic in ACP patients, which seems that the allergic condition may be coincident with the polyps but have no significantly contribution to their pathogenesis.

Up to now, the pathophysiology of ACPs has not yet been fully understood. Emerging evidence identified various cytokines and chemokines involved in the interaction of host and environmental factors during NP polypogenesis $[17,18]$, and comprehensive inflammatory pattern studies have been conducted to understand the pathogenesis of nasal polyps and guide clinical therapies $[9,10]$, but the key pathogenic mechanisms of ACPs are not completely elucidated. In this study, we investigated the characteristic of inflammatory profiles by Luminex in ACPs in the pediatric population to identify specific cytokines and to provide easily accessible biomarkers allocating patients specific therapies. To our knowledge, this is the first comprehensive study to investigate cytokines profiles for ACPs in children group.

Previous studies suggest that CRSwNP is usually characterized by type 2 T-helper $\left(\mathrm{T}_{\mathrm{H}} 2\right)$ response and tissue eosinophilia with elevated level of IL-5 [18]. Though eosinophilic inflammation has been described in the nasal mucosa of NP patients, the eosinophil-related cytokine IL-5 level had no significant difference between ACPs and control. As for chemokines, RANTES known to attract eosinophils $[19,20]$ and M-CSF often appears in the context of recruitment, activation, and survival of eosinophils [20,21], both of which were not upregulated in ACPs compared with control, further supporting the hypothesis that allergy could have a poor role in the pathogenesis of ACPs.

IL-6, a cytokine involved in the pathogenesis of various chronic inflammatory diseases, including crohn's disease, rheumatoid arthritis, asthma, and lupus [22-24]. Previous studies indicated that elevated IL-6 protein was observed in polyp tissue compared to middle turbinate in the same patients with CRSwNP [25]. Consistent with CRSwNP, we found the level of IL-6 was significantly increased in whole ACP compared to control, which can be considered as a possible therapeutic target and studies with anti-IL-6 monoclonal antibodies show auspicious results. In addition, our study demonstrated that there was a positive correlation between IL-6 and proinflammatory cytokines IL-1 $\beta$, meanwhile, the expression of neutrophil recruiting chemokines (GRO and IL-8) was positively correlated with IL-6, implying that IL-6 may enhance neutrophil recruitment to sites of infection.
Regulatory T (Treg) cells have been shown to inhibit Th1/Th2 response, and involve in the pathogenesis of respiratory allergic diseases [26]. Studies on regulatory $\mathrm{T}$ (Treg) cells in CRS are arising in recent years, but the results are controversial [27]. According to previous study, decreased Treg cells infiltration in ACP compared to NP and inferior turbinate mucosa from control on histopathology [28]. As a Treg related cytokine, IL-10 was increased in whole ACP compared to controls in our study. Besides, positively correlation between the expression of IL-10 and IL-4 and IL-13 was observed, indicating that Treg cell associated cytokine was involved in the inflammatory pathophysiological process of ACPs and played a certain regulatory role.

\section{Conclusion}

In conclusion, we found that nasal obstruction was the most common symptom in ACPs in children. Allergic condition may have a poor role in the pathogenesis of ACPs. ACPs were characterized by elevated expression of IL-6, which was correlated with levels of various markers for neutrophil recruitment in ACPs tissues, suggesting that IL-6 plays a crucial role in the pathogenesis of neutrophilic inflammation in patients with ACPs and may provide a new treatment strategy for ACPs in children. Treg cell associated cytokine IL-10 was involved in the inflammatory pathophysiological process of ACPs and played a certain regulatory role.

\section{Abbreviations \\ ACPs: antrochoanal polyps; VAS: visual analogue scale; IgE: immunoglobulin E; IL: interleukin; IFN: interferon; GRO: growth related oncogene; MIP: macrophage inflammatory protein; GM-CSF: granulocyte-macrophage colony-stimulating factor; MCP-1: monocyte chemotactic protein-1; RANTES: regulated on activation, normal $T$ cell expressed and secreted; TNF: tumor necrosis factor; IQR: interquartile range.}

\section{Acknowledgements}

Not applicable.

\section{Authors' contributions}

$J \mathrm{~L}, \mathrm{WTG}$, and XN conceived and designed the experiments. LXT, XJY, and PPW collected the samples. BBS and HWZ performed the experiments. PC and SJH analyzed the data. HWZ wrote the paper. All authors read and approved the final manuscript.

\section{Funding}

This study was supported by Beijing Postdoctoral Research Foundation (201822-115), Beijing Municipal Administration of Hospitals'Youth Programme, (QML20171202), and Beijing Health System Top Level Health Technical Personnel Training Plan (20153079)

\section{Availability of data and materials}

The datasets used and analysed during the current study are available from the corresponding author on reasonable request.

\section{Ethics approval and consent to participate}

This study was approved by the Ethics Committee of Beijing Children's Hospital, Capital Medical University and written informed consent was obtained from all participants. 


\section{Consent for publication \\ Not applicable.}

\section{Competing interests}

The authors declare that they have no competing interests.

\section{Author details \\ ${ }^{1}$ Beijing Key Laboratory for Pediatric Diseases of Otolaryngology, Head and Neck Surgery, MOE Key Laboratory of Major Diseases in Children, Beijing Pediatric Research Institute, Beijing Children's Hospital, Capital Medical University, National Center for Children's Health, Beijing, China. ${ }^{2} \mathrm{Head}$ and Neck Surgery, Beijing Children's Hospital, Capital Medical University, Beijing, China.}

\section{Received: 28 November 2018 Accepted: 13 June 2019}

Published online: 20 June 2019

\section{References}

1. Yaman H, Yilmaz S, Karali E, Guclu E, Ozturk O. Evaluation and management of antrochoanal polyps. Clin Exp Otorhinolaryngol. 2010;3(2):110-4

2. Aydin S, Taskin U, Orhan I, Altas B, Oktay MF, Toksoz M, et al. The analysis of the maxillary sinus volumes and the nasal septal deviation in patients with antrochoanal polyps. Eur Arch Otorhinolaryngol. 2015;272(11):3347-52

3. El-Sharkawy AA. Endoscopic management of paediatric antrochoanal polyp: our experience. Acta Otorhinolaryngol Ital. 2013;33(2):107-11.

4. Galluzzi F, Pignataro L, Maddalone M, Garavello W. Recurrences of surgery for antrochoanal polyps in children: a systematic review. Int J Pediatr Otorhinolaryngol. 2018;106:26-30

5. Choudhury N, Hariri A, Saleh H. Endoscopic management of antrochoanal polyps: a single UK centre's experience. Eur Arch Otorhinolaryngol. 2015;272(9):2305-11.

6. Myatt HM, Cabrera M. Bilateral antrochonanal polyps in a child: a case report. J Laryngol Otol. 1996;110(3):272-4.

7. Yamashiro Y, Nakamura M, Huang GW, Kosugi T. Presence of urokinasetype plasminogen activator (U-PA) in tissue extracts of antrochoanal polyp. Laryngoscope. 1992;102(9):1049-52.

8. Al-Mazrou KA, Bukhari M, Al-Fayez Al. Characteristics of antrochoanal polyps in the pediatric age group. Ann Thorac Med. 2009;4(3):133-6.

9. Li CW, Zhang KK, LiTY, Lin ZB, Li YY, Curotto de Lafaille MA, et al. Expression profiles of regulatory and helper T-cell-associated genes in nasal polyposis. Allergy. 2012;67(6):732-40

10. Wen W, Liu W, Zhang L, Bai J, Fan Y, Xia W, et al. Increased neutrophilia in nasal polyps reduces the response to oral corticosteroid therapy. J Allergy Clin Immunol. 2012;129(6):1522-8.

11. Cao PP, Zhang YN, Liao B, Ma J, Wang BF, Wang H, et al. Increased local IgE production induced by common aeroallergens and phenotypic alteration of mast cells in Chinese eosinophilic, but not noneosinophilic, chronic rhinosinusitis with nasal polyps. Clin Exp Allergy. 2014:44(5):690-700.

12. Lee DH, Yoon TM, Lee JK, Lim SC. Difference of antrochoanal polyp between children and adults. Int J Pediatr Otorhinolaryngol. 2016;84:143-6.
13. Nikakhlagh S, Rahim F, Saki N, Mohammadi H, Maliheh YM. Antrochoanal polyps: report of 94 cases and review the literature. Niger J Med. 2012;21(2):156-9.

14. Yuca K, Bayram I, Kiroglu AF, Etlik O, Cankaya H, Sakin F, et al. Evaluation and treatment of antrochoanal polyps. J Otolaryngol. 2006;35(6):420-3.

15. Maldonado M, Martinez A, Alobid I, Mullol J. The antrochoanal polyp. Rhinology. 2004;42(4):178-82

16. Yasmin T, Ghafoor F, MalikT, Khan AU. Pattern of thyroid autoimmunity in type 1 and type 2 diabetics. J Coll Physicians Surg Pak. 2006;16(12):751-4.

17. Wang BF, Cao PP, Long XB, Zhang XH, Xu K, Cui YH, et al. Distinct mucosal immunopathologic profiles in atopic and nonatopic chronic rhinosinusitis without nasal polyps in Central China. Int Forum Allergy Rhinol. 2016;6(10):1013-9.

18. Konig K, Klemens C, Haack M, Nicolo MS, Becker S, Kramer MF, et al. Cytokine patterns in nasal secretion of non-atopic patients distinguish between chronic rhinosinusitis with or without nasal polys. Allergy Asthma Clin Immunol. 2016;12:19

19. Kaplan AP. Chemokines, chemokine receptors and allergy. Int Arch Allergy Immunol. 2001;124(4):423-31.

20. Pawankar R. Nasal polyposis: an update: editorial review. Curr Opin Allergy Clin Immunol. 2003;3(1):1-6.

21. Leitner G, Loidolt H, Greinix HT, Hocker P, Dettke M. Granulocyte colonystimulating factor-induced allogeneic peripheral stem cell donation during early pregnancy. Br J Haematol. 2001;115(1):233-4.

22. Hirano T, Matsuda T, Turner M, Miyasaka N, Buchan G, Tang B, et al. Excessive production of interleukin 6/B cell stimulatory factor-2 in rheumatoid arthritis. Eur J Immunol. 1988;18(11):1797-801.

23. Houssiau FA, Devogelaer JP, Van Damme J, de Deuxchaisnes CN, Van Snick J. Interleukin-6 in synovial fluid and serum of patients with rheumatoid arthritis and other inflammatory arthritides. Arthritis Rheum. 1988;31(6):784-8.

24. Atreya R, Mudter J, Finotto S, Mullberg J, Jostock T, Wirtz S, et al. Blockade of interleukin 6 trans signaling suppresses T-cell resistance against apoptosis in chronic intestinal inflammation: evidence in crohn disease and experimental colitis in vivo. Nat Med. 2000;6(5):583-8.

25. Danielsen A, Tynning T, Brokstad KA, Olofsson J, Davidsson A. Interleukin 5, IL6, IL12, IFN-gamma, RANTES and Fractalkine in human nasal polyps, turbinate mucosa and serum. Eur Arch Otorhinolaryngol. 2006;263(3):282-9.

26. Palomares O, Yaman G, Azkur AK, Akkoc T, Akdis M, Akdis CA. Role of Treg in immune regulation of allergic diseases. Eur J Immunol. 2010:40(5):1232-40.

27. Stevens WW, Lee RJ, Schleimer RP, Cohen NA. Chronic rhinosinusitis pathogenesis. J Allergy Clin Immunol. 2015;136(6):1442-53.

28. Jin P, Zi X, Charn TC, Liu J, Yan Y, Shi L, et al. Histopathological features of antrochoanal polyps in Chinese patients. Rhinology. 2018;56(4):378-85.

\section{Publisher's Note}

Springer Nature remains neutral with regard to jurisdictional claims in published maps and institutional affiliations.

Ready to submit your research? Choose BMC and benefit from

- fast, convenient online submission

- thorough peer review by experienced researchers in your field

- rapid publication on acceptance

- support for research data, including large and complex data types

- gold Open Access which fosters wider collaboration and increased citations

- maximum visibility for your research: over 100M website views per year

At BMC, research is always in progress.

Learn more biomedcentral.com/submissions 